\title{
August Schmauss 75 Jahre alt
}

Am 26. November 1952 vollendet der Geheime Regierungsrat o. ö. Professor für Meteorologie em. an der Universität München August Schmauss sein 75. Lebensjahr. Aus diesem Anlaß hat sich ein Kreis von Kollegen, Schülern und früheren Mitarbeitern der Bayer. Forstlichen Forschungsanstalt und dem Meteorologischen Institut der Universität zusammengetan, um dem Jubilar das vorliegende Heft dieser Zeitschrift als Festgabe zu widmen. August Schmauss wurde 1877 in München geboren. Er promovierte 1900 mit einer Dissertation „Über anomale elektromagnetische Rotationsdispersion". Im Frühjahr 1906 wurde er 1. Adjunkt an der Bayer. Meteorologischen Zentralanstalt und blieb in dieser Stellung, bis er am 1. Dezember 1910 zum Direktor dieser Anstalt ernannt wurde. In das Jahr 1908 fällt seine Habilitation. 1917 wurde er zum Honorarprofessor ernannt, 1922 als Ordinarius an die Universität München berufen; kurz darauf wurde ein Lehrstuhl für Meteorologie dort erstmals errichtet, den Geheimrat Schmauss bis zu seiner Emeritierung im Jahre 1948 innehatte.

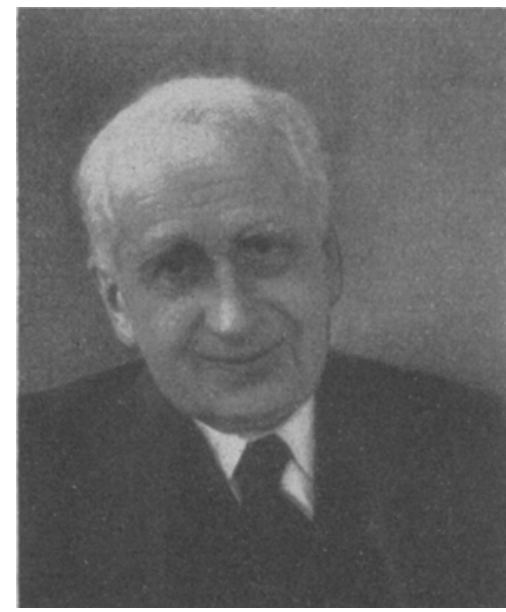
Zahl seiner wissenschaftlichen Veröffentlichungen (eine Zusammenstellung findet sich in der Meteorologischen Rundschau 1947) sei nur auf einige Arbeiten hingewiesen, die forstlich besonders aktuelle Probleme behandeln, nämlich "Uber Sturmgefährdung " (Forstw. Cbl. 1920), „Die Frühjahrskälterückfälle" (Forstw. Cbl. 1930), „Gedanken über Klimaschwankungen“ (Mitt. Akad. d. Forstw. 1942), "Der Klimaraum der Jungpflanze" (ebenda 1941). Auch die in zwei Auflagen erschienene Schrift "Wetterkunde und Landwirtschaft" (Berlin 1912 u. 1925) muß erwähnt werden. Es wäre ferner auf eine größere Ânzahl grundlegender und für die Entwicklung der Forstwissenschaft äußerst fruchtbarer Forschungsarbeiten hinzuweisen, die im Münchener Forstmeteorologischen Institut unter der Leitung von Scrimauss entstanden sind und zumeist im Forstwissenschaftlichen Centralblatt veröffentlicht wurden.

Mit besonderer Hingabe hat Geheimrat Schmauss sich stets dem akademischen Unterricht gewidmet, und man darf wohl einen wesentlichen - vielleicht sogar den fruchtbarsten. Teil seiner Lebensarbeit in dieser über ein Menschenalter sich erstreckenden Vorlesungstätigkeit erblicken. Eine ganze Generation von Forstwirten verdankt ihm die Einführung in das nicht leicht zugängliche Gebiet der Meteorologie, und viele Hunderte werden sich zeitlebens dieser überaus klaren und dabei in seltener Weise spannenden und lebendigen Vorträge erinnern.

Die Entbindung von den formellen Pflichten bedeutet bei ScHmauss keineswegs einen Ruhestand. Nach wie vor bereichert er den akademischen Unterricht mit Vorlesungen, wie sie nur souveräne Beherrschung eines Fachgebietes und ein universeller Geist zu gestalten vermögen; nach wie vor steht er mit Amtsnachfolger und früheren Mitarbeitern in enger Fühlung und lebendiger Zusammenarbeit. Wir dürfen wünschen, daß ihm noch lange Jahre voll Gesundheit, Tätigkeit und Lebensfreude beschieden sein möchten! 